\title{
Kajian Pengaruh Intensitas Suara Terhadap Bangunan Cagar Budaya Berbahan Batu Tahap II
}

\section{Study of the Impact of Sound Intensity on Cultural Heritage Buildings}

\author{
Linus Setyo Adhidhuto, Jati Kurniawan, Nur Amri Susilo, \\ Puji Santoso, dan Ajar Priyanto \\ Balai Konservasi Borobudur \\ linus.setyo.a@gmail.com
}

\begin{abstract}
ABSTRAK
Kegiatan konser musik atau acara lainnya yang menggunakan sound system dengan intensitas besar sering dilaksanakan di Candi Borobudur, Candi Prambanan serta candi-candi lainnya. Hal ini menimbulkan kekhawatiran di kalangan pelestari cagar budaya akan dampak buruk suara keras yang dihasilkan oleh speaker terhadap cagar budaya. Suara merupakan gelombang mekanik yang menjalar pada medium padat, cair dan gas. Gelombang ini dapat ditangkap oleh bangunan menjadi respon getaran. Bila respon getaran ini melebihi batas ambang getaran yang dimiliki bangunan maka dapat mengakibatkan kerusakan struktur pada bangunan.

Pada kajian ini dilakukan pengukuran respon getaran yang terjadi pada beberapa candi batu saat berlangsung kegiatan konser musik dan event lainnya yang bersuara keras. Pengamatan kebisingan dilakukan dengan membandingkan intensitas suara di depan sumber suara dan yang sampai ke candi dengan menggunakan sound level meter. Untuk mengetahui respons bangunan terhadap suara maka dilakukan pengukuran getaran yang timbul pada permukaan batu candi menggunakan vibration analyzer. Untuk menentukan batas ambang intensitas suara yang diperbolehkan di lingkungan cagar budaya digunakan perhitungan dengan menggunakan rumus perubahan intensitas suara terhadap jarak. Dari nilai intensitas ini dapat ditentukan besarnya daya speaker yang dianjurkan di lingkungan Candi Borobudur.

Pengukuran amplitudo getaran akibat suara konser di Candi Borobudur mencapai maksimal 0,0338 mm/s, masih jauh dari batas ambang getaran kejut oleh Kementerian Lingkungan Hidup sebesar $2 \mathrm{~mm} / \mathrm{s}$. Hal ini mengindikasikan bahwa dengan adanya konser musik yang berlangsung pada tahun 2017 dan 2018 tidak menimbulkan getaran yang berbahaya bagi struktur candi, baik itu getaran pada lantai, komponen pemikul beban dan batu teratas. Dari hasil kajian ini juga ditetapkan batas intensitas suara di depan speaker pada titik-titik yang sering digunakan sebagai panggung. Penetapan batas ambang ini didasarkan pada kesehatan manusia yang berada di lingkungan candi, mengingat kecilnya dampak suara terhadap bangunan dan struktur cagar budaya berbahan batu.
\end{abstract}

Kata Kunci: intensitas suara; respon getaran; cagar budaya; konser musik

\begin{abstract}
Music concerts or other events that use large sound systems are often held at Borobudur Temple, Prambanan Temple and other temples. These events raise concerns among cultural heritage's preserver about the adverse effects of loud sounds produced by speakers on cultural heritage. Sound is a mechanical wave that propagates in a solid, liquid and gas medium. This wave can be transmitted by the building into a vibrational response. If the
\end{abstract}


vibration response exceeds the vibration threshold of the building, it can cause structural damage to the building.

In this study, the vibration response measurements are done in several stone temples during music concerts and other loud events. Noise observations are done by comparing the intensity of the sound in front of the speaker and in the temple using sound level meter. To find out the response of the temple building because of the sound, vibration measurement are done on the stone surface using a vibration analyzer. To determine the threshold of sound intensity allowed in a cultural heritage environment, a calculation using formula of the change of sound intensity to distance is used. From this sound intensity value, can be determined the amount of speaker power recommended in the Borobudur Temple area.

The speed of vibration due to sound of concerts reached $0,0338 \mathrm{~mm} / \mathrm{s}$ which is far from shock vibration threshold for ancient building $(2 \mathrm{~mm} / \mathrm{s})$ according to Ministry of Environment regulation. This indicates that the music concerts that happen in 2017 and 2018 does not produce vibrations that cause harmful effect to the temple. In this research, we also determine the sound intensity threshold in several area in Borobudur temple which are often used for music concerts. Because the harmful effect of sound to the temples are not significant, the determination of sound intensity threshold is based on human health.

Keywords: sound pressure level; vibration response; cultural heritage; music concert

\section{PENDAHULUAN}

Ancaman terhadap bangunan dan struktur cagar budaya semakin hari semakin banyak dan kompleks. Candi Borobudur dan Candi Prambanan contohnya, dengan semakin populernya kedua candi tersebut maka semakin banyak ancaman yang beresiko merusak material dan struktur candi.

Salah satu dampak dari semakin populernya kedua candi tersebut adalah semakin seringnya diadakan kegiatan atau konser musik yang menggunakan sound system dengan daya yang besar di area sekitar candi. Festival Borobudur Jazz, perayaan Waisak di Candi Borobudur, Prambanan Jazz serta Sendratari Ramayana di Prambanan adalah beberapa contoh kegiatan yang rutin diselenggarakan. Suara merambat melalui medium udara, padat dan cair. Gelombang suara yang dihasilkan speaker menggetarkan udara yang kemudian merambat terus sampai ke permukaan batu candi yang diikuti dengan bergetarnya batu candi. Bila suara tersebut memiliki energi yang besar maka akan menimbulkan getaran yang cukup besar pada batu candi, bahkan pada beberapa kasus sampai menggetarkan kaca-kaca di rumah penduduk yang lebih jauh jaraknya. Tindakan pencegahan harus dilakukan, namun demikian penggunaan area sekitar candi untuk kegiatan-kegiatan tersebut tentu saja tidak bisa dilarang begitu saja sehingga harus diatur penggunaan sound system di area tersebut agar tidak memberikan dampak negatif pada bangunan candi.

Pada kajian ini diamati bagaimana pengaruh gelombang suara dengan intensitas tertentu terhadap getaran yang timbul pada candi. Amplitudo kecepatan getaran diukur besarnya kemudian dibandingkan dengan batas ambang yang telah ditetapkan oleh pemerintah melalui Keputusan Menteri Lingkungan Hidup no KEP 49/MENLH/11/1996. Pada peraturan 
tersebut telah diatur batas ambang getaran mekanik dan getaran kejut pada bangunan dengan nilai budaya tinggi.

\section{Maksud dan Tujuan}

Maksud dari dilaksanakannya kajian ini adalah mengetahui dampak dari suara keras yang dikeluarkan oleh speaker terhadap kelestarian cagar budaya batu. Sedangkan tujuan dari kajian ini adalah untuk memberikan rekomendasi mengenai aturan intensitas suara, penempatan speaker, serta durasi suara di lingkungan cagar budaya khususnya Candi Borobudur.

\section{DASAR TEORI}

Getaran adalah perulangan dari suatu sistem mekanik atau struktur terhadap titik kesetimbangannya (Kelly, 2000). Getaran yang merambat disebut dengan gelombang. Gelombang terbagi menjadi 2 jenis yaitu gelombang elektromagnetik yang tidak membutuhkan medium untuk merambat dan gelombang mekanik yang membutuhkan medium untuk merambat. Suara termasuk gelombang mekanik yang bisa merambat melalui medium padat, cair dan gas. Berdasarkan cara rambatnya, gelombang terbagi menjadi dua yaitu gelombang transversal dan gelombang longitudinal. Gelombang transversal memiliki arah getaran yang tegak lurus dengan arah rambatnya, sedangkan gelombang longitudinal memiliki arah getaran yang searah dengan arah rambatnya (Pain, 2005).

Getaran dan kebisingan merupakan dua hal yang berbeda. Dalam kajian ini, getaran yang dimaksud adalah getaran muncul pada material candi akibat terkena suara, sedangkan kebisingan merupakan intensitas suara yang dihasilkan oleh speaker. Pemerintah telah mengatur batas ambang kebisingan melalui Kementerian Lingkungan Hidup dan Kementerian Tenaga Kerja dan Transmigrasi. Batas ambang pada kedua aturan tersebut merujuk pada dampaknya kepada manusia, bukan kepada kelestarian material dan struktur cagar budaya. Kementerian Lingkungan Hidup melalui Keputusan Menteri Lingkungan Hidup no KEP48/MENLH/11/1996 mengatur baku tingkat kebisingan pada cagar budaya sebesar 60 dBA. Menurut aturan ini, maka kebisingan yang diperbolehkan di lingkungan cagar budaya hanya sebatas percakapan biasa, tidak lebih dari itu. Namun hal ini tentu saja sedikit bertolak belakang dengan kondisi sebenarnya di Candi Borobudur yang ramai pengunjung.

Tim kajian pada tahun 2018 berkesempatan konsultasi langsung ke Kementerian Lingkungan Hidup untuk menanyakan mengenai aturan ini. Hasil dari konsultasi tersebut adalah sebagai berikut

1. Baku ambang kebisingan yang ditetapkan pada aturan tersebut ditujukan untuk kesehatan manusia dan kenyamanan lingkungan yang ada di area cagar budaya, bukan untuk bangunan cagar budaya itu sendiri sehingga suara $60 \mathrm{dBA}$ belum tentu berbahaya bagi kelestarian candi/bangunan cagar budaya.

2. Kementerian Lingkungan Hidup belum memiliki ambang batas kebisingan yang berbahaya bagi bangunan.

3. Aturan kebisingan secara umum ini sedang dalam proses pengusulan 
untuk direvisi oleh Kementerian Lingkungan Hidup dan Kehutanan dengan pertimbangan pertumbuhan ekonomi tidak akan membuat keadaan menjadi lebih sunyi

Kementerian Tenaga Kerja dan Transmigrasi melalui peraturan Menteri nomor PER13/MEN/X/2011 tentang Nilai Ambang Batas Faktor Fisika dan Faktor Kimia di tempat kerja telah mengatur batas ambang kebisingan yang bisa diterima manusia dalam durasi tertentu dalam sehari (Tabel 1)

Tabel 1. Durasi dan intensitas suara maksimal menurut aturan Kementerian Tenaga Kerja dan Transmigrasi

\begin{tabular}{cc}
\hline $\begin{array}{c}\text { Waktu pemaparan } \\
\text { (jam) }\end{array}$ & $\begin{array}{c}\text { Intensitas suara } \\
\text { dalam dBA }\end{array}$ \\
\hline 8 & 85 \\
\hline 4 & 88 \\
\hline 2 & 91 \\
\hline 1 & 94 \\
\hline
\end{tabular}

Jika dibandingkan antara kedua aturan kebisingan tersebut maka aturan dari Kementerian Tenaga Kerja dan Transmigrasi ini lebih relevan untuk diterapkan dalam membatasi kebisingan yang ada di lingkungan cagar budaya akibat adanya konser musik atau event bersuara keras lainnya. Aturan dari Kementerian Lingkungan Hidup hanya membatasi kebisingan sebesar 60 dBA untuk cagar budaya, sedangkan pada saat konser di beberapa candi besar di Indonesia telah melebihi nilai tersebut (Adhidhuto, 2017). Dari data yang selalu melebihi batas ambang ini, maka penggunaan aturan dari Kementerian Lingkungan Hidup sebagai acuan pembatasan kebisingan saat konser dan event bersuara keras lainnya sudah tidak memungkinkan.

Pada tahun 1996, Menteri Lingkungan Hidup menetapkan Baku Tingkat Getaran untuk kenyamanan dan kesehatan, getaran berdasarkan dampak kerusakan, serta getaran berdasarkan jenis bangunan yang tertuang pada KEP 49/MENLH/11/1996. Pada peraturan tersebut getaran terbagi menjadi dua yaitu getaran mekanik dan getaran kejut. Yang dimaksud getaran mekanik adalah getaran yang ditimbulkan oleh sarana dan peralatan kegiatan manusia. Getaran jenis ini berlangsung secara terus-menerus hampir setiap harinya. Beberapa contoh getaran mekanik yaitu getaran dari kendaraan bermotor dan getaran dari aktifitas pembangunan. Getaran kejut adalah getaran yang terjadi secara tiba-tiba dan sesaat. Contoh dari getaran jenis ini yaitu gempa bumi, ledakan bom, kecelakaan, dan sebagainya.

Untuk penerapan baku ambang getaran yang lebih relevan diterapkan di lingkungan cagar budaya pada saat berlangsung konser adalah baku ambang getaran kejut karena hanya berlangsung sesekali dengan durasi yang terbatas. Baku ambang getaran kejut tersebut dapat dilihat pada Tabel 2.

\section{METODE PENELITIAN}

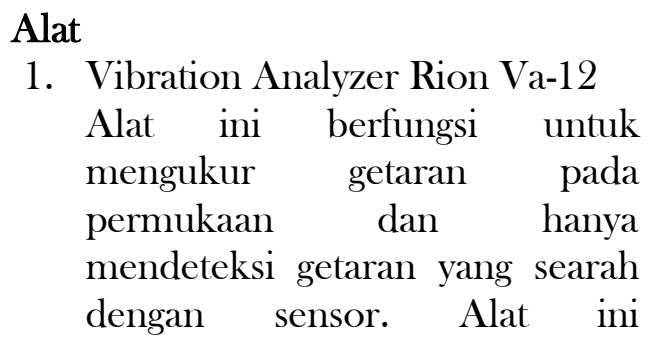


Tabel 2. Tabel 2 Baku tingkat getaran kejut berdasarkan jenis bangunan (KEP - 49/ MENLH/ 11/ 1996)

\begin{tabular}{clc}
\hline Kelas & \multicolumn{1}{c}{ Jenis Bangunan } & $\begin{array}{c}\text { Kecepatan } \\
\text { Getaran } \\
\text { Maksimum } \\
\text { (mm/detik) }\end{array}$ \\
\hline 1 & $\begin{array}{l}\text { Peruntukan dan } \\
\text { bangunan kuno yang } \\
\text { mempunyai nilai sejarah } \\
\text { yang tinggi }\end{array}$ & 2 \\
\hline \multirow{2}{*}{$\begin{array}{l}\text { Bangunan dan kerusakan } \\
\text { yang sudah ada, tampak } \\
\text { keretakan-keretakan pada } \\
\text { tembok }\end{array}$} & 5 \\
\hline & $\begin{array}{l}\text { Bangunan untuk dalam } \\
\text { kondisi teknis yang baik, } \\
\text { ada kerusakan-kerusakan } \\
\text { kecil seperti : plesteran } \\
\text { yang retak }\end{array}$ \\
\hline & $\begin{array}{l}\text { Bangunan "kuat” } \\
\text { (misalnya : bangunan } \\
\text { industri terbuat dari } \\
\text { beton atau baja) }\end{array}$ \\
\hline
\end{tabular}

menggunakan sensor piezoelectric accelerometer dan memiliki rentang frekuensi $3 \mathrm{~Hz}$ - 20 kHz. Percepatan getaran yang mampu dideteksi berada pada kisaran $0,02-141,4 \mathrm{~m} / \mathrm{s}^{2}$.

2. Sound Level Meter Extech HD600

Alat ini berfungsi mengukur tingkat kebisingan dengan rentang pengukuran antara $30 \mathrm{~dB}$ hingga 130 dB. Tingkat akurasi alat ini mencapai $1,4 \mathrm{~dB}$.

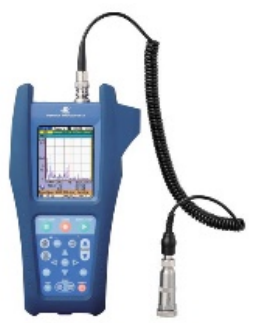

(a)

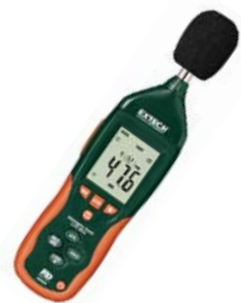

(b)

Gambar 1 (a) Vibration Analyzer RIon VA-12 dan (b) Sound Level Meter Extech HD-600

\section{Rancangan Pengambilan Data}

\section{Pengukuran kebisingan dan getaran akibat suara pada bangunan candi}

Pada pengukuran ini, digunakan dua buah sound level meter dimana satu buah sound level meter diletakkan tepat di depan sumber suara untuk mengetahui intensitas suara sumber, dan satu lagi diletakkan pada candi untuk mengetahui intensitas suara yang sampai pada candi. Penggunaan dua sound level meter di depan sumber suara dan di candi bertujuan untuk membandingkan suara yang sampai ke candi dengan suara yang dihasilkan oleh sumber suara. Suara yang sampai pada candi pasti lebih rendah intensitasnya dibandingkan dengan di depan sumber suara karena pengaruh jarak dan kondisi medium. Perbandingan intensitas di dua tempat ini bertujuan untuk menentukan jarak dan intensitas suara yang aman bagi kelestarian candi.

Perekaman suara juga dilakukan dengan menggunakan mikrofon agar suara tersebut bisa dianalisa spektrumnya dengan menggunakan program komputer. Dari data spektrum ini bisa diketahui frekuensi dominan dari konser atau kegiatan yang berlangsung di 
lingkungan candi. Bila frekuensi dominan memiliki nilai yang sama dengan frekuensi natural batu maka getaran yang timbul pada batu candi akan berlipat ganda.

Vibration analyzer memiliki sensor piezoelectric accelerometer yang nantinya ditempelkan pada dinding candi untuk merekam data getaran yang timbul. Penempelan sensor ini harus dilakukan dengan hati-hati karena terkena sedikit goncangan saja maka data yang diperoleh tidak valid.

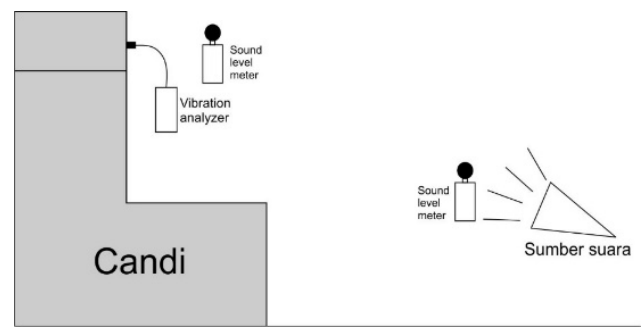

Gambar 2. Skema peletakan alat dan pengambilan data

\section{Penentuan batas ambang kebisingan, jarak speaker, daya speaker serta arah hadap speaker di lingkungan Candi Borobudur}

Penentuan batas ambang ini dilakukan dalam dua tahap. Tahap pertama yaitu menentukan batas ambang kebisingan dalam desibel yang diperbolehkan di titik-titik yang sering didirikan panggung pada zona 1 dan zona 2 Candi Borobudur.

Pada tahap kedua dilakukan perhitungan mengenai sensitivitas speaker dan hubungan antara daya amplifier dengan intensitas suara yang dikeluarkan speaker. Speaker memiliki nilai sensitivitas tertentu dimana tidak semua energi listrik yang diberikan akan diubah menjadi energi suara, sebagian diubah ke energi panas dan kinetik. Dari tahap ini kemudian dapat ditentukan berapa daya speaker maksimal yang diperbolehkan di lingkungan zona 1 dan zona 2 Candi Borobudur.

\section{HASIL PENELITIAN}

\section{Pengaruh Intensitas Suara Terhadap Bangunan Cagar Budaya Berbahan}

Batu

Pengukuran getaran pada kajian ini menggunakan alat Vibration Meter merk Rion VA-12. Alat ini ditempelkan pada permukaan batu di bagian paling atas Candi Borobudur (pagar langkan) dimana pada batu ini tidak terdapat beban tambahan dari atas sehingga dapat lebih bebas bergetar.

Dengan semakin minimnya redaman getaran ini maka diharapkan getaran yang ditimbulkan akibat suara akan lebih keras. Rangkuman hasil

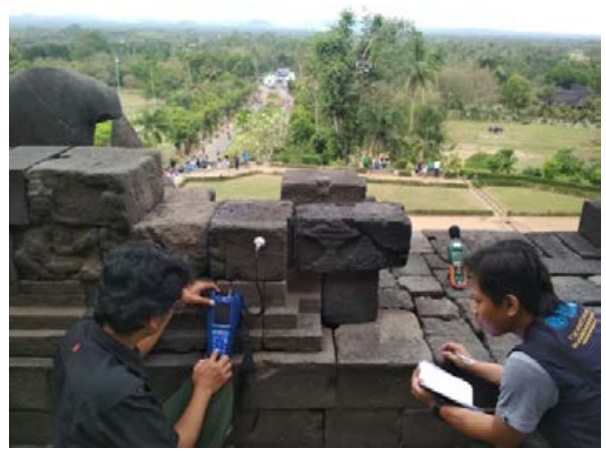

Gambar 3. Pengukuran intensitas suara dan getaran di Pagar Langkan Lorong 2

Timur Candi Borobudur pada acara Yamaha Maxi Day

pengukuran kebisingan dan getaran pada saat berlangsung konser atau event lainnya di Candi Borobudur dapat dilihat pada Tabel 3. 
Tabel 3. Data amplitudo kecepatan getaran pada beberapa konser dan acara lainnya di candi Borobudur

\begin{tabular}{|c|c|c|c|c|c|c|c|c|}
\hline \multirow{2}{*}{ Kegiatan } & \multirow{2}{*}{$\begin{array}{l}\text { Lokasi } \\
\text { Panggung }\end{array}$} & \multicolumn{2}{|c|}{$\begin{array}{l}\text { Intensitas suara } \\
\text { maksimal (dBC) }\end{array}$} & \multicolumn{2}{|c|}{$\begin{array}{l}\text { Intensitas suara } \\
\text { rata-rata }(\mathrm{dBC})\end{array}$} & \multirow{2}{*}{$\begin{array}{l}\text { Perbedaan } \\
\text { intensitas } \\
\text { suara rata- } \\
\text { rata }(\mathrm{dBC})\end{array}$} & \multicolumn{2}{|c|}{ Getaran maksimal } \\
\hline & & Sumber & Candi & Sumber & Candi & & $\begin{array}{c}\text { Kecepatan } \\
(\mathrm{mm} / \mathrm{s})\end{array}$ & $\begin{array}{c}\text { Frekuensi } \\
(\mathrm{Hz})\end{array}$ \\
\hline $\begin{array}{l}\text { Peluncuran } \\
\text { Vivo }\end{array}$ & $\begin{array}{l}\text { Marga } \\
\text { Utama }\end{array}$ & 123,3 & 95 & 97,95 & 72,46 & 25,49 & 0,029 & 3,125 \\
\hline $\begin{array}{l}\text { Borobudur } \\
\text { International } \\
\text { Arts \& Culture }\end{array}$ & Lumbini & 127,7 & 85,7 & 89,73 & 66,72 & 23,01 & 0,0199 & 3,125 \\
\hline $\begin{array}{l}\text { Yamaha Maxi } \\
\text { Day }\end{array}$ & $\begin{array}{l}\text { Marga } \\
\text { Utama }\end{array}$ & 123,4 & 87,2 & 103,86 & 70,31 & 33,55 & 0,024 & 3,125 \\
\hline $\begin{array}{l}\text { Perayaan } \\
\text { Asadha }\end{array}$ & Kenari & 121,8 & 98,4 & 77,03 & 67,58 & 9,45 & 0,024 & 3,125 \\
\hline $\begin{array}{l}\text { Perayaan } \\
\text { Waisak }\end{array}$ & Kenari & 126,5 & 88,2 & 87,06 & 71,29 & 15,77 & 0,0338 & 3,125 \\
\hline
\end{tabular}

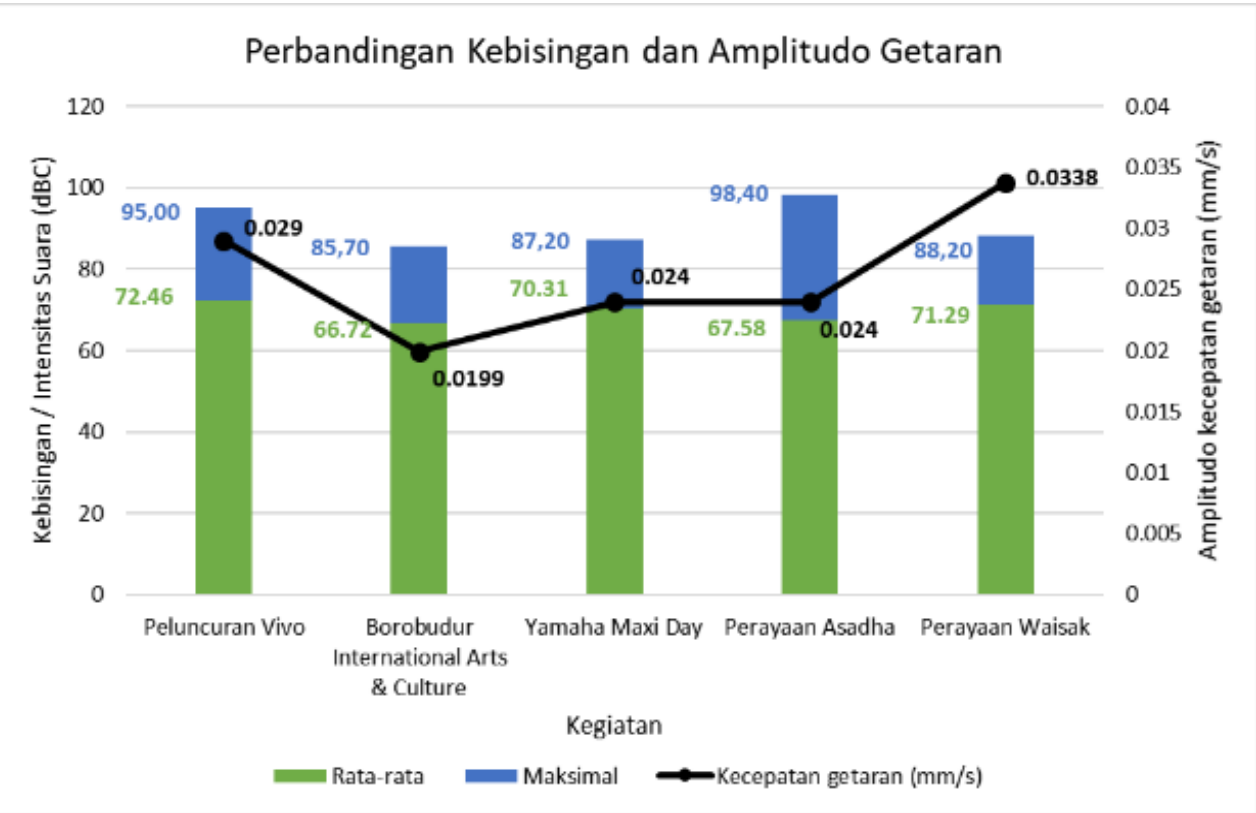

Gambar 4. Perbandingan Intensitas suara maksimal terhadap getaran yang dihasilkan pada pengukuran di Candi Borobudur tahun 2018

Dari Tabel 3, dapat diketahui bahwa intensitas suara tertinggi di depan speaker yang terukur adalah sebesar 127,7 dBC pada acara Borobudur International Arts \& Culture tanggal 6-8 Juli 2018. Sedangkan intensitas suara tertinggi yang terukur sampai ke Candi Borobudur adalah pada saat acara perayaan Indonesia Tipitaka Chanting and Asadha Mahapujua (tanggal 2022 Juli 2018) sebesar 98,4 dBC. Meskipun intensitas suara terbesar yang sampai ke Candi Borobudur adalah pada perayaan Asadha namun getaran terbesar muncul pada saat perayaan Waisak dimana pada saat itu intensitas suara maksimal yang sampai ke candi hanya mencapai 88,2 dBC. Perbandingan intensitas suara dan 


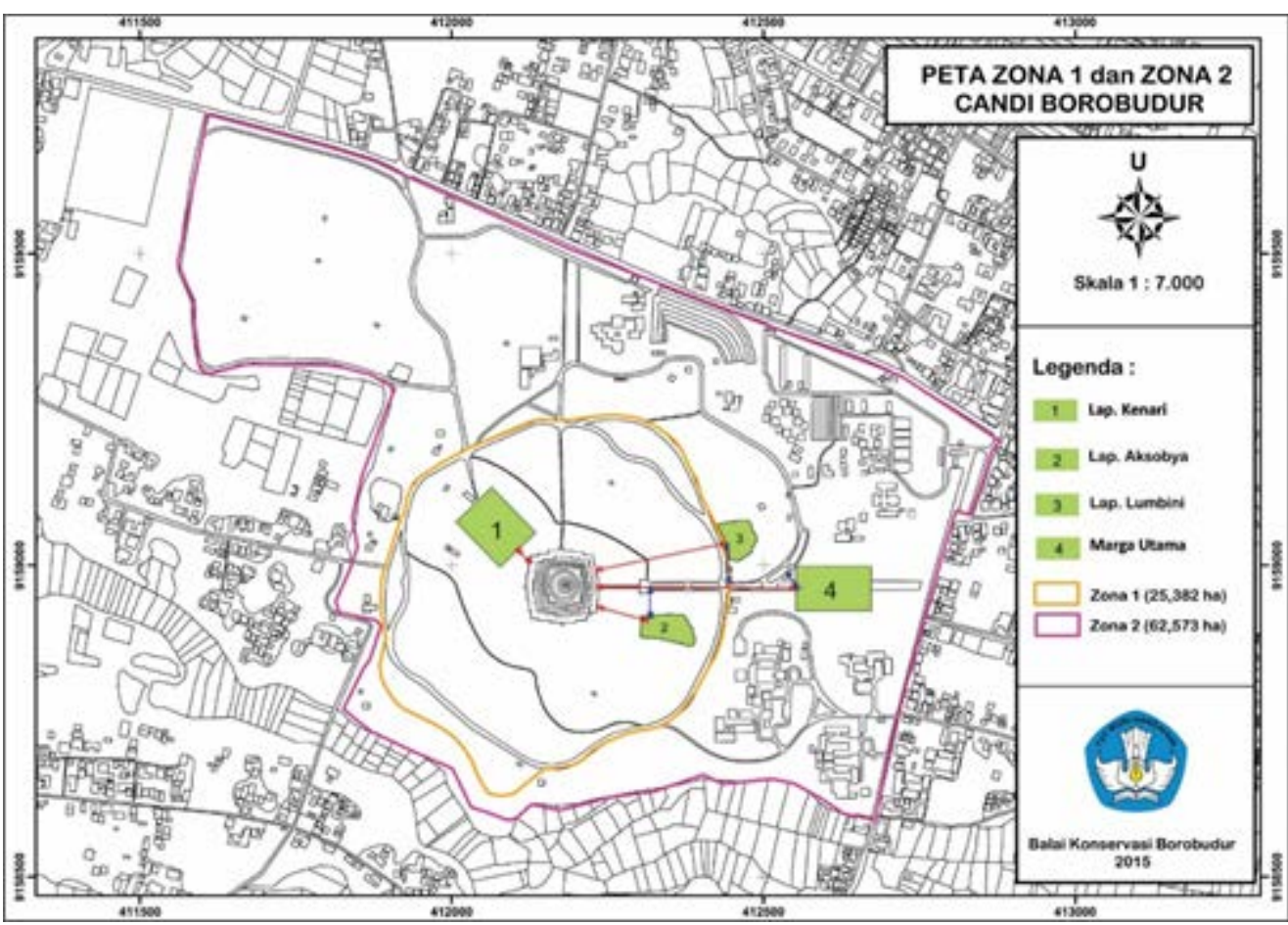

Gambar 5. Peta lokasi di Candi Borobudur yang sering digunakan untuk konser atau event bersuara keras lainnya

getaran yang muncul dapat dilihat pada Gambar 4. Amplitudo getaran terbesar pada acara Waisak mencapai $0,0338 \mathrm{~mm} / \mathrm{s}$. Nilai ini masih sangat jauh di bawah batas ambang getaran kejut yang ditetapkan Kementerian Lingkungan Hidup yaitu sebesar 2 $\mathrm{mm} / \mathrm{s}$ atau hanya mencapai $1,69 \%$ dari batas ambang. Dari data ini mengindikasikan bahwa suara dari konser atau event lainnya dengan intensitas suara yang mencapai 98,4 dBC belum memberikan dampak berupa getaran yang berbahaya terhadap Candi Borobudur. Namun demikian getaran merupakan efek jangka pendek, sehingga harus dilakukan kajian lebih lanjut untuk mengetahui dampaknya terhadap cagar budaya dalam jangka panjang.

\section{Penentuan Batas Ambang Kebisingan di Candi Borobudur}

Penentuan batas ambang kebisingan tidak dapat dilakukan berdasarkan respon getaran yang timbul pada batu candi karena amplitudo getaran yang sangat kecil. Dampak kebisingan itu sendiri selain berimbas pada cagar budaya juga memberikan dampak pada manusia yang berada di lingkungan candi. Paparan kebisingan dengan intensitas sangat tinggi dalam waktu singkat atau intensitas cukup tinggi pada waktu lama memberikan dampak tersendiri bagi kesehatan manusia salah satunya terhadap organ pendengaran.

Pada pengukuran kebisingan sebelumnya dalam rangka mencari dampak getaran pada permukaan candi digunakan mode dBC. Hal ini dilakukan karena dibutuhkan data suara dari segala frekuensi untuk ditinjau pengaruhnya terhadap getaran yang timbul. Namun karena pengaturan batas ambang kebisingan 
ini lebih ditujukan untuk manusia, maka mode pengukuran kebisingan menggunakan mode dBA.

Kebisingan adalah bunyi yang tidak diinginkan (Kementerian Lingkungan Hidup, 1996). Manusia cenderung untuk tahan pada suara yang cukup tinggi intensitasnya bila memang kondisi tersebut sudah dipersiapkan secara mental. Contoh kasus adalah manusia yang menonton konser musik rock. Suara dari speaker dapat mencapai 120 dBA (Resnick, 2007) namun kebanyakan penonton menikmati kondisi tersebut. Meskipun demikian jika hal ini sering terjadi maka dalam waktu lama organ pendengaran akan mengalami pelemahan. Hal ini yang harus dihindari oleh manusia yang berada di lingkungan cagar budaya, dalam hal ini pengunjung umum dan petugas di lapangan.

Penentuan batas ambang kebisingan ditentukan oleh faktor jarak dimana semakin jauh sumber suara maka intensitas suara yang sampai akan semakin kecil. Perubahan besar intensitas suara terhadap jarak dirumuskan sebagai berikut (Ahnert, 2017):

$$
L_{1}=L_{2}+20 \log \left(\frac{R_{2}}{R_{1}}\right)
$$

L merupakan intensitas suara $(\mathrm{dB})$ dan $\mathrm{R}$ merupakan jarak (m). Titik 1 merupakan sumber suara, berada pada jarak 1 meter $\left(R_{1}\right)$ di depan speaker sesuai dengan prinsip pengukuran sensitifitas speaker. Titik 2 merupakan tempat pengunjung yang paling dekat dengan sumber suara. Karena dampak suara lebih banyak kepada pengunjung serta petugas daripada kepada bangunan cagar budaya itu sendiri, maka tidak digunakan jarak ke candi untuk pengukuran jarak titik kedua.

Terdapat empat tempat di zona 1 dan 2 Candi Borobudur yang sering dimanfaatkan untuk konser maupun acara lainnya. Keempat tempat tersebut adalah Lapangan Kenari, Lapangan Aksobya (zona 1), Lapangan Lumbini dan Marga utama (zona 2) yang dapat dilihat pada Gambar 5. Jarak $\mathrm{R}_{2}$ dari keempat lokasi tersebut ke jalur pengunjung disebutkan pada Tabel 5 .

Tabel 5 Jarak panggung dari Candi Borobudur dan jalur pengunjung

\begin{tabular}{llcc}
\hline No & Lokasi & $\begin{array}{c}\text { Jarak dari } \\
\text { Candi }\end{array}$ & $\begin{array}{c}\text { Jarak dari jalur } \\
\text { pengunjung }\left(\mathrm{R}_{2}\right)\end{array}$ \\
\hline 1 & Kenari & $30 \mathrm{~m}$ & $30 \mathrm{~m}$ \\
\hline 2 & Aksobya & $100 \mathrm{~m}$ & $30 \mathrm{~m}$ \\
\hline 3 & Lumbini & $220 \mathrm{~m}$ & $65 \mathrm{~m}$ \\
\hline 4 & Marga & $350 \mathrm{~m}$ & $15 \mathrm{~m}$ \\
& Utama & & \\
\hline
\end{tabular}

Dari Tabel 5 tersebut dapat ditentukan batas ambang intensitas suara yang diperbolehkan menggunakan rumus di atas. Misalkan akan dilaksanakan konser di Lapangan Lumbini dengan durasi empat jam, maka batas ambang kebisingan yang diperbolehkan di jalur pengunjung dengan jarak terdekat 60 $\mathrm{m}$ dari Lumbini adalah sebesar 88 dBA. Intensitas suara maksimal di depan speaker agar menghasilkan suara maksimal sebesar $88 \mathrm{dBA}$ di jalur pengunjung adalah sebagai berikut

$$
\begin{aligned}
& L_{\text {lumbini }}=L_{2}+20 \log \left(\frac{R_{2}}{R_{1}}\right) \\
& \begin{aligned}
L_{\text {lumbibi }}= & 85+20 \log \left(\frac{65}{1}\right) \\
= & 85+36,258 \\
& =121,26 \mathrm{dBA}
\end{aligned}
\end{aligned}
$$


Tabel 6 Batas ambang intensitas suara dan durasi untuk masing-masing lokasi panggung di Candi Borobudur

\begin{tabular}{|c|c|c|c|c|c|c|c|c|}
\hline \multirow{2}{*}{ Lokasi panggung } & \multicolumn{7}{|c|}{ Intensitas suara (dBA) } \\
\cline { 2 - 9 } & $\mathbf{8}$ jam & $\mathbf{7}$ jam & $\mathbf{6}$ jam & $\mathbf{5}$ jam & $\mathbf{4}$ jam & $\mathbf{3}$ jam & $\mathbf{2}$ jam & $\mathbf{1}$ jam \\
\hline Kenari & 114,54 & 115,12 & 115,79 & 116,57 & 117,54 & 118,79 & 120,54 & 123,54 \\
\hline Aksobya & 114,54 & 115,12 & 115,79 & 116,57 & 117,54 & 118,79 & 120,54 & 123,54 \\
\hline Lumbini & 121,26 & 121,84 & 122,51 & 123,29 & 124,26 & 125,51 & 127,26 & 130,26 \\
\hline Marga Utama & 108,52 & 109,10 & 109,77 & 110,55 & 111,52 & 112.77 & 114,52 & 117,52 \\
\hline
\end{tabular}

Jadi, intensitas maksimal yang diperbolehkan pada jarak 1 meter di depan speaker di lapangan Lumbini adalah sebesar 121,26 dBA. Perhitungan ini kemudian dilakukan untuk keempat lokasi yang sering digunakan untuk konser, seperti terlihat pada Tabel 6 .

Untuk memudahkan dalam pengawasan dan pelaksanaan pembatasan di lapangan, maka batas ambang kebisingan tersebut dapat di konversi kedalam daya speaker yang diperbolehkan. Penentuan daya speaker ditentukan oleh sensitifitas speaker. Sensitifitas speaker adalah kemampuan speaker untuk mengubah daya amplifier menjadi suara. Energi yang dikeluarkan dari amplifier ini tidak semuanya dikonversi menjadi energi suara, namun juga menjadi energi panas, energi kinetik membran speaker dan sebagainya sehingga terdapat energi yang hilang. Sensitifitas speaker dihitung dari berapa desibel yang dihasilkan oleh daya 1 watt amplifier pada jarak 1 meter. Secara umum speaker konser memiliki sensitifitas sekitar 88 dBA. Sesuai dengan rumus

$$
\text { Intensitas }=10 \log _{10}\left(\frac{I}{I_{0}}\right) d B A
$$

maka penambahan daya sebesar $2 \mathrm{kali}$ lipat akan meningkatkan intensitas suara sebesar $3 \mathrm{dBA}$. Dari pernyataan tersebut bisa dibuat tabel intensitas suara yang dihasilkan dari daya speaker tertentu.

Tabel 7. Daya speaker yang dibutuhkan untuk menghasilkan intensitas suara pada jarak 1 meter dengan mempertimbangkan sensitifitas speaker sebesar 88dB

\begin{tabular}{|c|c|}
\hline $\begin{array}{c}\text { Intensitas pada } \\
\text { jarak } 1 \mathrm{~m}\end{array}$ & $\begin{array}{c}\text { Daya Speaker } \\
\text { (W) }\end{array}$ \\
\hline 88 & 1 \\
\hline 91 & 2 \\
\hline 94 & 4 \\
\hline 97 & 8 \\
\hline 100 & 16 \\
\hline 103 & 32 \\
\hline 106 & 64 \\
\hline 109 & 128 \\
\hline 112 & 256 \\
\hline 115 & 512 \\
\hline 118 & 1024 \\
\hline 121 & 2048 \\
\hline 124 & 4096 \\
\hline 127 & 8192 \\
\hline 130 & 16384 \\
\hline 133 & 32768 \\
\hline 136 & 65536 \\
\hline
\end{tabular}

Dari tabel tersebut kemudian diplot ke dalam grafik Ln seperti terlihat pada Gambar 6 . 
Diperoleh persamaan garis dengan fungsi $\ln$ dimana $\mathrm{y}=4,3281 \ln$ $(\mathrm{x})+88$ dimana $\mathrm{y}$ merupakan intensitas suara $(\mathrm{dB})$ dan $\mathrm{x}$ merupakan (Watt). Untuk dapat mengkonversi satuan daya menjadi intensitas suara maka dilakukan perhitungan sebagai berikut :

$$
\begin{gathered}
y=4,3281 \ln (x)+88 \\
y-88=4,3281 \ln (x) \\
\ln (x)=\frac{y-88}{4,3281} \\
x=e^{\left(\frac{y-88}{4,3281}\right)}
\end{gathered}
$$

Sehingga untuk dapat memperoleh besar daya speaker yang dibutuhkan untuk menghasilkan suara sebesar y dB pada jarak 1 meter dipergunakan rumus tersebut. Contoh kasus: Berapa daya speaker yang diperlukan untuk bisa menghasilkan suara dengan intensitas sebesar 127,26 dB pada jarak 1 meter dari speaker

$$
\begin{aligned}
x=e^{\left(\frac{127,26-88}{4,3281}\right)} & =e^{9,071 \times 10^{-4}} \\
= & 8698,9 \\
= & 8699 \text { Watt }
\end{aligned}
$$

Jadi untuk bisa menghasilkan suara sebesar 127,26 dB, maka diperlukan speaker dengan daya sebesar 8.699 Watt

Perhitungan tersebut dilakukan juga pada batas ambang kebisingan lainnya di Lapangan Kenari, Aksobya, Lumbini, dan Marga Utama seperti terlihat pada Tabel 8.

\section{Grafik daya speaker terhadap intensitas suara pada} jarak $1 \mathrm{~m}$

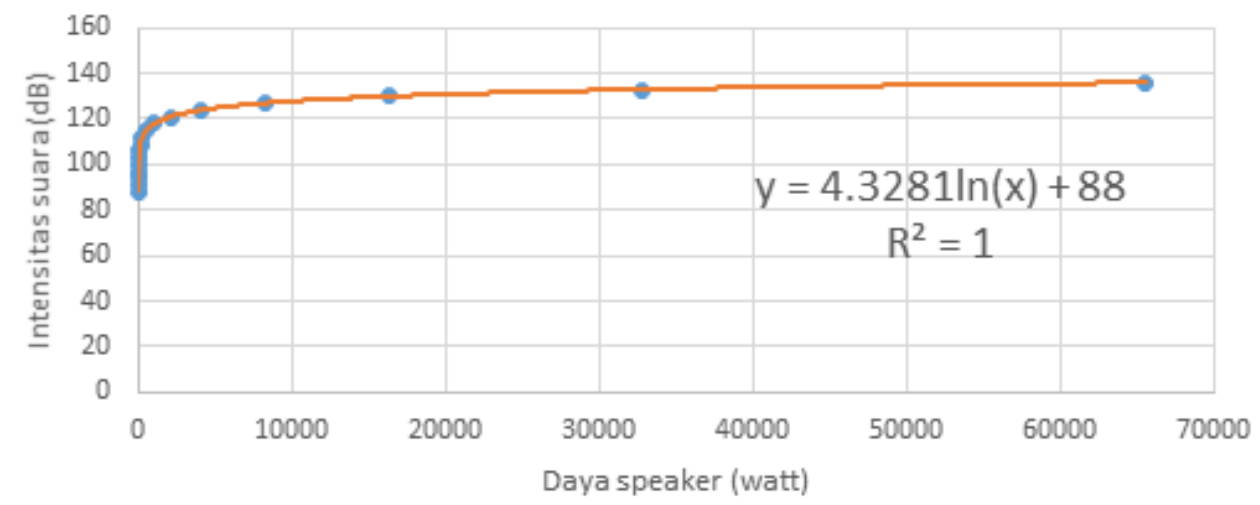

Gambar 6. Grafik daya speaker terhadap intensitas suara yang dihasilkan pada jarak $1 \mathrm{~m}$

Tabel 8 Batas ambang daya speaker untuk masing-masing lokasi panggung dengan mempertimbangkan sensitifitas speaker sebesar $88 \mathrm{~dB}$

\begin{tabular}{|l|c|c|c|c|c|c|c|c|}
\hline \multirow{2}{*}{ Lokasi panggung } & \multicolumn{7}{|c|}{ Daya Speaker (Watt) } \\
\cline { 2 - 10 } & $\mathbf{8}$ jam & $\mathbf{7}$ jam & $\mathbf{6}$ jam & $\mathbf{5}$ jam & $\mathbf{4}$ jam & $\mathbf{3}$ jam & $\mathbf{2 ~ j a m}$ & $\mathbf{1}$ jam \\
\hline Kenari & 460 & 526 & 615 & 736 & 921 & 1229 & 1841 & 3683 \\
\hline Aksobya & 460 & 526 & 615 & 736 & 921 & 1229 & 1841 & 3683 \\
\hline Lumbini & 2175 & 2487 & 2903 & 3476 & 4349 & 5806 & 8699 & 17398 \\
\hline Marga Utama & 115 & 131 & 153 & 183 & 229 & 306 & 458 & 916 \\
\hline
\end{tabular}


Perlu diketahui, bahwa Tabel 8 berlaku untuk speaker secara umum dimana sensitivitasnya berkisar pada $88 \mathrm{~dB}$ dan dilakukan dalam kondisi volume penuh. Batas ambang tersebut tidak berlaku bila speaker diatur bukan pada volume penuh. Pada umumnya, pihak penyelenggara acara tidak akan mengatur speaker pada volume penuh karena akan mengakibatkan suara menjadi terdengar pecah dan tidak nyaman. Oleh karena itu diperlukan monitoring kebisingan pada saat berlangsung acara sehingga ketika suara melebihi batas ambang yang ditetapkan maka dapat memberikan arahan kepada panitia untuk mengecilkan volume.

\section{KESIMPULAN}

1. Hasil dari pengukuran dengan menggunakan vibration meter yang telah dilakukan pada beberapa kegiatan di Candi Borobudur 2018 menunjukkan bahwa getaran yang muncul di batu candi akibat suara keras dari speaker sangat kecil, hanya mencapai nilai maksimal 0,0338 $\mathrm{mm} / \mathrm{s}$. Nilai ini masih jauh dari ambang batas getaran yang ditetapkan oleh Kementerian Lingkungan Hidup melalui Kep49/MENLH/11/1996, yaitu sebesar $2 \mathrm{~mm} / \mathrm{s}$. Dari data ini bisa disimpulkan bahwa suara keras dari konser yang dilaksanakan di lingkungan cagar budaya tidak berbahaya dalam jangka pendek bagi struktur dan bangunan cagar budaya berbahan batu.

2. Meskipun dalam jangka pendek tidak berdampak buruk, namun mengingat kegiatan konser musik berlangsung dengan durasi yang cukup lama dan frekuensi kegiatan yang cukup sering, dampak suara dalam jangka panjang terhadap kelestarian bangunan candi masih belum diketahui. Belum ada sumber literatur ilmiah yang sudah meneliti hal tersebut. Hal ini masih menjadi kekhawatiran bila ternyata memang ada dampak buruk suara keras dalam jangka waktu yang panjang.

3. Dengan mempertimbangkan faktor pengunjung umum serta petugas yang ada di lingkungan cagar budaya maka direkomendasikan durasi acara dan batas ambang kebisingan pada titik-titik konser di Candi Borobudur yang dapat dilihat pada Tabel 6. Penempatan speaker dapat dilakukan pada titik tersebut namun dengan arah yang membelakangi candi dan jalur pengunjung agar suara yang sampai ke candi dan pengunjung dalam diminimalisir.

\section{SARAN}

1. Dengan mempertimbangkan durasi dan frekuensi acara dengan suara keras di lingkungan candi, maka perlu dilakukan pengamatan dan pengujian dampak dari suara berintensitas tinggi dalam waktu lama terhadap material cagar budaya batu.

2. Sebagai salah satu upaya untuk mengurangi kebisingan akibat konser baik itu di Candi Borobudur maupun pada jalur pengunjung, maka direkomendasikan untuk memasang peredam suara di titik- 
titik tertentu. Pemasangan peredam dapat berupa pohon yang rindang dan berdaun lebar. Pohon rindang dengan lebar barisan 15-30 meter dapat menurunkan kebisingan hingga 6-10 dB (Reethof, 1973). Penanaman pohon ini dapat dilakukan di sisi utara dan barat Lapangan Aksobya, sisi barat dan selatan Lapangan Lumbini di zona 2, serta sisi barat hingga utara lapangan Marga Utama.

3. Telah diperoleh batas ambang daya speaker berdasarkan sensitifitas speaker 88 dB. Namun batas ambang ini tidak bersifat mutlak karena sangat bervariasinya spesifikasi sensitifitas speaker di lapangan. Bila daya speaker yang digunakan tidak melebihi ambang batas maka tidak perlu dilakukan monitoring kebisingan karena dapat dipastikan bahwa suara yang mencapai candi tidak akan melebihi batas ambang. Namun bila daya speaker yang digunakan melebihi maka harus dilakukan monitoring kebisingan dengan tujuan dapat mengontrol suara sehingga tidak melebihi batas ambang.

\section{UCAPAN TERIMA KASIH}

Terima kasih kepada narasumber kajian Dr. Mitrayana, S.Si., M.Si selaku dosen Departemen Fisika, Universitas Gadjah Mada, yang telah membimbing tim kajian dari tahap penyusunan proposal hingga selesainya kajian ini. 


\section{DAFTAR PUSTAKA}

Adhidhuto, Linus Setyo, dkk. (2017). Kaj̈an Pengaruh Intensitas Suara Terhadap Bangunan Cagar Budaya Berbahan Batu (Kajian). Magelang: Balai Konservasi Borobudur.

Ahnert, Wolfgang dan Steffen, Frank. (2017). Sound Reinforcement Engineering: Fundamentals and Practice. CRC Press.

Kelly, S. Graham. (2000). Fundamental of Mechanical Vibrations. Mc-Graw Hill.

Kementerian Lingkungan Hidup. (1996). Keputusan Menteri Negara Lingkungan

Hidup No KEP-48/MENLH/11/1996 Tentang Baku Tingkat Kebisingan. Jakarta: Menteri Negara Lingkungan Hidup.

Kementerian Lingkungan Hidup. (1996). Keputusan Menteri Negara Lingkungan

Hidup No KEP-49/MENLH/1 1/1996 Tentang Baku Tingkat Getaran. Jakarta:

Menteri Negara Lingkungan Hidup.

Kementerian Tenaga Kerja dan Transmigrasi. (2011). Peraturan Menteri Tenaga

Kerja dan Transmigrasi No PER.13/MEN/X/2011 Tentang Nilai Ambang

Batas Faktor Fisika dan Faktor Kimia di Tempat Kerja. Jakarta: Menteri Tenaga Kerja dan Transmigrasi.

Pain, H. J. (2005). The Physics of Vibrations and Waves. John Wiley \& Sons.

Reethof, G. (1973). Effect of Plantings on Radiation of Highway Noise. Journal of The Air Pullotion Control Association 23, 185-189

Resnics, Robert, Halliday, David, and Walker, Jearl. (2007). Fundamental of Physics, 10th ed. John Willey \& Sons.

Steffens, R. J. (1974). Structural Vibration and Damage. Departement of the Environtment, Building Research Station.

Taman Wisata Candi Borobudur. (2017). Data Pengunjung Lebaran 2016 -2017.

Wahyuningsih, Isni, Puspitasari, Dian Eka dan Prasetyoko, Yuli Harry. (2009).

Kajian Carrying Capacity Candi Borobudur (Kajian). Magelang: Balai Konservasi Borobudur. 